Nunt. Antiquus, Belo Horizonte, v. 17, n. 1, p. 131-151, 2021

\title{
Tradução dos discursos de Messala no Diálogo dos Oradores
}

\section{Translation of Messalla's speeches in the Dialogus de Oratoribus}

Victor Chabu

Universidade de São Paulo (USP), São Paulo, São Paulo / Brasil

victor.chabu@usp.br

https://orcid.org/0000-0001-9219-1796

Resumo: Apresentamos uma tradução em português dos discursos de Vipstano Messala no Diálogo dos Oradores, de Tácito, bem como o texto latino em que nos baseamos. A tradução foi feita com especial cuidado relativo ao jargão de doutrina retórica presente na obra.

Palavras chave: Diálogo dos Oradores. Tácito. Retórica latina. Vipstano Messala. Tradução.

Abstract: We present a translation into Portuguese of the speeches of Vipstanus Messalla in the Dialogus de Oratoribus of Tacitus, as well as the Latin text taken as its basis. The translation was carried out with special care relatively to the rhetorical jargon present in the work.

Keywords: Dialogus de Oratoribus. Tacitus. Roman rhetoric. Vipstanus Messalla. Translation.

\section{Introdução}

Tácito iniciou sua vida pública como orador durante o reinado de Nero, e, sendo um homo nouus, alguém sem pais ou ancestrais que tivessem exercido altos cargos políticos, subiu os degraus da carreira pública impulsionado por seu talento (e talvez com alguma ajuda de um bom casamento), até atingir o posto de cônsul sufecto em 97 d.C., 
sob Domiciano. Por esse tempo, Roma já vivia em um sistema político centralizado na figura do princeps, o imperador, havia 130 anos, e a geração de Tácito chegava à maturidade marcada pelo rescaldo desse e de outros governos tirânicos que marcaram o séc. I.

Por volta de 102 d.C., no início da época de Trajano, que promoveu uma reabertura política, Tácito publica o Diálogo dos Oradores, cuja ação dramática é ambientada durante o reinado de Vespasiano, provavelmente em 75 d.C., um intervalo de paz frágil e bastante tensa entre o pavoroso ano dos quatro imperadores e o governo truculento de Domiciano. Os oradores do Diálogo, portanto, também acreditavam viver um período de estabilização, como os contemporâneos de Tácito, mas dentro de uma década estariam diante de novas proscrições, ${ }^{1}$ um deles, Curiácio Materno, aproveitou a suposta calma sob Vespasiano para, por assim dizer, falar com a antiga franqueza, uti antiqua libertate (Dial. 27.3), e por conta disso teria acabado condenado à morte e executado, provavelmente em 91 d.C., após um demorado processo ao longo de 15 anos e 3 reinados.

É nesse clima de apreensão, de uma nova paz que, até ali, era no máximo presumível, que o Diálogo começa como uma carta de Tácito a Fábio Justo, continuando o que seria uma discussão frequente entre eles: cur, cum priora saecula tot eminentium oratorum ingeniis gloriaque floruerint, nostra potissimum aetas deserta et laude eloquentiae orbata uix nomen ipsum oratoris retineat ${ }^{2}$ (Dial. 1.1). À guisa de resposta, põe-se a rememorar um debate que ouvira décadas antes, entre oradores exímios; um deles, Materno, recitara sua tragédia Catão e com ela incomodara pessoas poderosas, por isso seus amigos Júlio Segundo e Marco Apro foram-no visitar no dia seguinte, a fim de convencê-lo a amenizar o enredo e torná-la não necessariamente meliorem (melhor), mas pelo menos securiorem (mais segura). Materno não apenas não aceita retificar Catão, como promete ser ainda mais crítico em Tiestes, sua próxima tragédia.

$\mathrm{O}$ debate entre Materno e Apro, em que discutiam a prevalência da retórica sobre a poética, e a legitimidade de uma e de outra, já ia bastante animado quando, logo após uma intervenção de Materno

\footnotetext{
${ }^{1}$ Condenação (geralmente por denúncias de corrupção) dos inimigos políticos à morte ou ao exílio, e subsequente apreensão de todos seus bens, e repartição desses entre o imperador e seus aliados.

2 Por que, tendo tido gerações anteriores que floresceram com o talento e o sucesso de tantos oradores de renome, é sobretudo a nossa época, estéril e órfã de reverência pela oratória, que a custo preserva até mesmo a designação de orador.
} 
particularmente ácida contra os oradores contemporâneos, aparece pela porta de seu cubículo um curioso Vipstano Messala, interrompendo-os: "num parum tempestiuus interueni secretum consilium et causae alicuius meditationem tractantibus?"3 (Dial. 14.1).

"Não, de jeito nenhum", responde Júlio Segundo, outro dos oradores, "e até gostaria que tivesses aparecido mais cedo, pois te teriam deleitado tanto a fala muitíssimo pertinente do nosso querido Apro, que exortava Materno a redirecionar toda a sua inteligência e o seu esforço aos processos judiciais, quanto o discurso de Materno em favor dos seus poemas, um discurso alegre, como convém para defender um poeta, bastante ousado e mais parecido com o dos poetas que com o de um orador" (Dial. 14.2). Messala não hesita em rapidamente tomar parte da conversa:

"me uero", inquit," H $^{+}$sermo iste infinita uoluptate affecisset, atque id ipsum delectat quod uos, uiri optimi et temporum nostrorum oratores, non forensibus tantum negotiis et declamatorio studio ingenia uestra exercetis, sed eius modi etiam disputationes assumitis quae et ingenium alunt et eruditionis ac litterarum iucundissimum oblectamentum cum uobis, qui ista disputatis, afferunt, tum etiam iis ad quorum aures peruenerint."

"itaque hercule non minus probari uideo in te, Secunde, quod Iuli Africani uitam componendo spem hominibus fecisti plurium eius modi librorum, quam improbari in Apro quod nondum ab scholasticis controuersiis recessit et otium suum mauult nouorum rhetorum more quam ueterum oratorum consumere. "' (Dial. 14.3-4)

3 "Por acaso apareci em uma hora ruim, tratáveis de alguma deliberação privada e da preparação de algum processo?"

${ }^{4}$ Em Heubner (1983) há um et que deletei.

5 "A mim, sinceramente", diz ele, "essa conversa me teria enchido de imensa satisfação, e deleita-me o próprio fato de vós, pessoas excelentes e oradores do nosso tempo, não estardes exercitando os vossos talentos apenas com questões judiciais e com a prática da declamação, mas de vos engajardes assim também em debates que nutrem a inteligência e proporcionam o enorme prazer da cultura literária, a vós mesmos, que debateis tais assuntos, e ainda mais àqueles a cujos ouvidos eles chegarem."

"É por isso, oras, que não considero menos elogiável em ti, Segundo, que ao escrever a biografia de Júlio Africano tenhas gerado nas pessoas a expectativa de mais publicações do tipo, do que acho criticável em Apro que ainda não se tenha retirado das controvérsias escolares e que goste de gastar o seu tempo livre mais ao modo dos rétores modernos que ao dos antigos oradores." 
Apro, irritadiço como no resto do texto, passa a resmungar que Messala não faz outra coisa que não desprezar os contemporâneos e endeusar os antigos, que ninguém dos tempos de então era um orador de verdade, como os antigos, e que ele era assim audacioso, pensa, porque Messala não recearia que ele e seu irmão ficassem com fama de serem maldosos. ${ }^{6}$ Messala returca:

"neque illius", "inquit, sermonis mei paenitentiam ago, neque aut Secundum aut Maternum aut te ipsum, Aper, quamquam interdum in contrarium disputes, aliter sentire credo. ac uelim impetratum ab aliquo uestrum ut causas huius infinitae differentiae scrutetur ac reddat, quas mecum ipse plerumque conquiro. et quod quibusdam solacio est, mihi auget quaestionem, quia uideo etiam Graiis accidisse ut longius absit ab Aeschine et Demosthene Sacerdos iste Nicetes, et si quis alius Ephesum uel Mytilenas concentu scholasticorum et clamoribus quatit, quam Afer aut Africanus

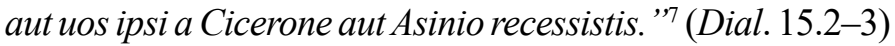

Segundo concorda que Messala trouxera uma questão interessante, digna de um tratamento mais extenso que não poderia ser melhor feito por ninguém senão o próprio Messala, que concorda em partilhar suas reflexões sobre o assunto, desde que os companheiros façam igualmente: "aperiam cogitationes meas si illud a uobis ante impetrauero, ut uos quoque sermonem hunc nostrum adiuuetis."8

${ }^{6}$ Provavelmente aludindo ao fato de que o meio-irmão de Messala, Marco Régulo, era um temido delator imperial e, pelo que se sabe das epístolas de Plínio, grande desafeto de Plínio e do próprio Tácito.

7 "Não me arrependo disso que digo", responde, "e não acho que nem Segundo, nem Materno, nem tu mesmo, Apro, ainda que de vez em quando discutas em contrário, pensem diferentemente. Gostaria que algum de vós examinasse e fornecesse as razões dessa diferença infinita, nas quais normalmente fico pensando eu comigo mesmo. E o que para alguns é motivo de consolo, para mim aumenta o problema, porque vejo que até com os gregos aconteceu de esse Nicetas Sacerdos - e quem mais for atarantar Efeso ou Mitilene com a ladainha e a barulheira das escolas de retórica - de ele estar mais longe de Ésquines e Demóstenes, do que Áfer ou Africano, ou mesmo do que vós vos afastastes de Cícero ou de Asínio."

8 "Eu posso compartilhar as minhas reflexões, se antes conseguir de vós que também vós contribuais com esta nossa discussão." 
Os outros oradores assentem, e assim começa o segundo discurso de Apro no Diálogo (Dial. 15.1-23.6), cuja estratégia se baseará em relativizar as noções de 'antigo' e 'contemporâneo', defender os oradores de sua geração como mais refinados, bem acabados, até mesmo por terem partido do trabalho dos antigos, e, claro, desancar como puder os tais antigos, não poupando nem mesmo a Cícero. Materno indigna-se, "estão vendo o que ele diz?", ou algo assim, e então cobra o posicionamento de Messala (Dial. 24.1), que virá em seu primeiro discurso; conforme veremos na Seção 1, Messala defenderá que os oradores de sua época não estão à altura dos antigos, porque não se educaram como os antigos se educavam, e não dominavam nem a retórica, nem a filosofia e nem o conhecimento jurídico como deveriam.

Em seguida, Materna retoma a palavra em Dial. 33.1 para solicitar que Messala detalhe os exercícios preparatórios com que os jovens das gerações passadas aprimoravam seus talentos. Vem, então, o segundo discurso de Messala, a partir de Dial. 33.4 (para nós, na Seção 2), que infelizmente encontra-se interrompido em Dial. 35.5; o resto do texto transmitido pelos manuscritos continua já em pleno segundo discurso de Materno, em que ele se dedica a caracterizar a oratória como um mal desestabilizador da sociedade (Dial. 41.2). O texto se encerra quando Messala, percebendo que já era tarde, dá a entender que a discussão continuaria em outro momento: "erant quibus contra dicerem, erant de quibus plura dici uellem, nisi iam dies esset exactus", (Dial. 42.1).

Apesar da interação aparentemente amistosa, a intervenção, talvez a intromissão de Messala no debate tem sido objeto de atenção por parte da crítica. Nada menos, Messala era meio-irmão de Marco Régulo, um temido delator ${ }^{10}$ e notório desafeto de Tácito. Não deve ter sido sem um certo incômodo, ao acabar de atacar os delatores e a "oratória lucrativa e sanguinolenta" (Dial. 12.2) de seus dias, que ele se

\footnotetext{
9 "Tem algumas coisas que eu retrucaria, outras das quais gostaria que fosse falado mais, se o dia já não se tivesse esvaído."

${ }^{10}$ Os delatores eram quem fazia as denúncias nas proscrições, e eram tanto mais odiados quanto escolhiam como alvo cada vez menos apenas os opositores do regime, e cada vez mais inimizades pessoais ou indivíduos que, simplesmente, eram ricos (eles e o imperador ficavam com parte dos bens dos proscritos).
} 
deu conta de que o irmão do pior deles estava do lado de fora da porta e possivelmente ouvira tudo. Já é estranho que o Diálogo se tenha dado em um cubículo, distante dos espaços abertos e públicos em que outros diálogos da Antiguidade costumavam acontecer, e só contribui para o clima geral de tensão a ironia com que os oradores se despedem: Materno, levantando-se, brinca dizendo a Apro que o denunciaria para os poetas, e Messala para os arcaizantes; e Apro conclui: "at ego uos rhetoribus et scholasticis" "1l (Dial. 42.2). Messala não diz nada, os oradores riem, mas Tácito mesmo não ri - talvez por saber qual seria o desfecho da história?

Neste trabalho traduzimos os trechos remanescentes dos discursos de Messala. Na coluna esquerda das seções abaixo há o texto latino correspondente aos discursos de Messala, para qual nos baseamos majoritariamente em Heubner (1983), com emendas de Mayer (2005) e Winterbottom e Olgivie (1975) e, em menor grau, de Gudeman (1894); na direita expomos uma tradução própria, cotejada com Bornecque e Goelzer (1906) e Requejo (1981), em que se considerou o conteúdo especializado de termos presentes na doutrina retórica latina, sobretudo de extração ciceroniana; uma descrição quase exaustiva desse vocabulário encontra-se em Clauseret (1886). Por fim, haverá notas de apoio após as referências, identificadas por algarismos romanos; aquelas atinentes ao estabelecimento do texto latino continuarão vindo como notas de rodapé usuais, enumeradas com algarismos arábicos na própria página em que forem indicadas.

\section{O primeiro discurso, Dial. 25.1 - 32.7}

Aqui, Messala defenderá que os oradores de sua época não estão à altura dos antigos, em resposta ao segundo discurso de Apro (Dial. 15.1-23.6), cuja estratégia se baseara em relativizar as noções de 'antigo' e 'contemporâneo'.

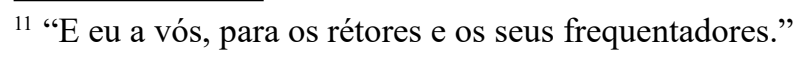


25.1 tum Messalla: "sequar praescriptam a te, Materne, formam. neque enim diu contra dicendum est Apro, qui primum, ut opinor, nominis controuersiam mouit, tamquam parum proprie antiqui uocarentur quos satis constat ante centum annos fuisse."

25.2 "mihi autem de uocabulo pugna non est, siue illos antiquos, siue maiores, siue quo alio mauult nomine appellet, dum modo in confesso sit eminentiorem illorum temporum eloquantiam fuisse."

"ne illi quidem parti sermonis eius repugno [qua fatetur] ${ }^{12}$ plures formas dicendi etiam iisdem saeculis, nedum diuersis extitisse."

25.3 "sed quo modo inter Atticos oratores primae Demostheni tribuuntur, proximum autem locum Aeschines et Hyperides et Lysias et Lycurgus obtinent, omnium tamen concessu haec oratorum aetas maxime probatur, sic apud nos Cicero quidem ceteros eorundem temporum disertos antecessit, Caluus autem et Asinius et Caesar et Caelius et Brutus iure et prioribus et sequentibus anteponuntur."

25.4 "nec refert quod inter se specie differunt, cum genere consentiant; adstrictior Caluus, neruosior Asinius, splendidior Caesar, amarior Caelius, grauior Brutus, uehementior et plenior et ualentior Cicero." "omnes tamen eandem sanitatem eloquentiae prae se ferunt, ut si omnium pariter libros in manum sumpseris, scias, quamuis in diuersis ingeniis, esse quandam iudicii ac uoluntatis similitudinem et cognationem."
25.1 Então Messala: "vou seguir o roteiro delineado por ti, Materno. Também não é por muito tempo que Apro precisará discursar pela parte contrária, ele que, penso eu, foi o primeiro a levantar o debate sobre terminologia, como se fosse pouco apropriado chamar de antigos aqueles que, sabe-se bem, existiram há mais de cem anos."

25.2 "Para mim, no entanto, não é caso de discutir o vocábulo, defina-os ele como antigos, como ancestrais, ou com qualquer outro nome que prefira, contanto que fique bem estabelecido que a eloquência daquela época era mais destacada."

"Não objeto nem sequer àquela parte da fala de Apro em que reconhece a existência de diversos estilos de discurso já em uma mesma época, quanto mais em épocas diferentes.”

25.3 "Agora, do mesmo modo como entre os oradores áticos o protagonismo é atribuído a Demóstenes, e o segundo lugar são Ésquines, Hipérides, Lísias e Licurgo que ocupam - no fim, todos concordam que são os oradores dessa geração que são os mais apreciados -, entre nós é de fato Cícero que se sobressaiu ante os demais bem falantes contemporâneos seus, e Calvo, Asínio, César, Célio e Bruto que, merecidamente, são preferidos tanto aos seus predecessores quanto aos seus sucessores."

25.4 "E pouco importa que diferem entre si no estilo ${ }^{13}$ conquanto concordem no gênero; Calvo é mais sucinto, Asínio mais substancioso, César mais reluzente, Célio mais ácido, Bruto mais sério, Cícero mais incisivo, mais vigoroso e mais escorreito."

"Todos, no entanto, apresentam o mesmo bom gosto oratório, de forma que, se tomares nas mãos escritos de todos igualmente, saberás que há, por mais que em talentos distintos, uma certa semelhança, um certo parentesco de gosto e de intenção."

\footnotetext{
12 Sugestão de Mayer (2005); em Heubner (1983), quominus fatear, e em Winterbottom e Olgivie (1975), si cominus fatetur, as quais não aparentam ter sentido.

${ }^{13}$ No latim, species, "aparência", que se encaixa dentro do conceito mais amplo de genus; um mesmo gênero textual comporta vários diferentes estilos de escrita.
} 
25.5 "nam quod inuicem se obtrectauerunt et sunt aliqua epistulis eorum inserta ex quibus mutua malignitas detegitur, non est oratorum uitium, sed hominum."

25.6 "nam et Caluum et Asinium et ipsum Ciceronem credo solitos et inuidere et liuere et ceteris humanae infirmitatis uitiis affici. solum inter hos arbitror Brutum non malignitate nec inuidia, sed simpliciter et ingenue iudicium animi sui detexisse. an ille Ciceroni inuideret, qui mihi uidetur ne Caesari quidem inuidisse?"

25.7 "quod ad Seruuim Galbam et Caium Laelium atttinet et si quos alios antiquorum agitare Aper non destitit, non exigit defensorem, cum fatear quaedam eloquentiae eorum ut nascenti adhuc nec satis adultae defuisse."

26.1 "ceterum si omisso optimo illo et perfectissimo genere eloquentiae eligenda sit forma dicendi, malim hercle C. Gracchi impetum aut L. Crassi maturitatem quam calamistros Maecenatis aut tinnitus Gallionis, adeo melius est orationem uel hirta toga induere quam fucatis et meretriciis uestibus insignire.

26.2 "neque enim oratorius iste, immo hercle ne uirilis quidem cultus est, quo plerique temporum nostrorum actores ita utuntur, ut lasciuia uerborum et leuitate sententiarum et licentia compositiones histrionales modos exprimant."
25.5 "Ora, o fato de que eles se detratavam mutuamente e de que há nas cartas deles alguns trechos nos quais se revela uma malícia recíproca não é um defeito dos oradores, mas dos homens."

25.6 "Afinal, creio que tanto Calvo como Asínio e o próprio Cícero estavam acostumados a invejar, a cobiçar e a sofrer dos demais defeitos da fraqueza humana. Acho que Bruto foi o único dentre eles que revelava as suas próprias convicções simples e francamente, sem malícia ou inveja. Ou ele teria inveja de Cícero, ele que, me parece, não teve inveja nem mesmo de César?"

25.7 "O que tange a Sérvio Galba e a Caio Lélio, e se a outros dos antigos que Apro não deixou de espezinhar, não demanda defensor, embora eu conceda que algumas coisas faltaram à oratória deles quando nascente, e ainda agora quando não suficientemente madura."

26.1 "Além disso, desconsiderando esse gênero de oratória excelente e tão perfeito, se fosse para escolher uma forma de eloquência, eu certamente preferiria o ímpeto de um Caio Graco ou a maturidade de um Lúcio Crasso do que os floreios de Mecenas ou os tinidos de Galião, a tal ponto é melhor vestir um discurso talvez até em uma toga rústica, ${ }^{14}$ do que enfeitá-lo com as roupas coloridas do meretrício.”

26.2 "Pois não é algo próprio de um orador, aliás não é nem algo próprio de um homem essa afetação de que a maioria dos advogados de hoje em dia faz tanto uso, que acabam por emular trejeitos teatrais com a licenciosidade do vocabulário, a leviandade das frases de efeito e os excessos de liberdade da composição."

\footnotetext{
${ }^{14}$ No original, hirta toga, expressão utilizada já em Inst. Orat. 12.10.7, uma referência à veste (e aos valores) da antiga tradição romana.
} 
26.3 "quodque uix auditu fas esse debeat, laudis et gloriae et ingenii loco plerique iactant cantari saltarique commentarios suos. unde oritur illa foeda et praepostera, sed tamen frequens $\dagger^{15}$ exclamatio, ut oratores nostri tenere dicere, histriones diserte saltare dicantur."

26.4 "equidem non negauerim Cassium Seuerum, quem solum Aper noster nominare ausus est, si iis comparetur qui postea fuerunt, posse oratorem uocari, quamquam in magna parte librorum suorum plus bilis habeat quam sanguinis. primus enim contempto ordine rerum, omissa modestia ac pudore uerborum, ipsis etiam quibus utitur armis incompositus et studio feriendi plerumque deiectus, non pugnat, sed rixatur."

26.5 "ceterum, ut dixi, sequentibus comparatus et uarietate eruditionis et lepore urbanitatis et ipsarum uirium robore multum ceteros superat, quorum neminem Aper nominare et uelut in aciem educere sustinuit."

26.6 "ego autem exspectabam ut, incusato Asinio et Caelio et Caluo, aliud nobis agmen produceret pluresque uel certe totidem nominaret, ex quibus alium Ciceroni, alium Caesari, singulis deinde singulos opponeremus."

26.7 "nunc detrectasse nominatim antiquos oratores contentus neminem sequentium laudare ausus est nisi in publicum et in commune, ueritus credo ne multos offenderet si paucos excerpsisset."
26.3 "E muitos se gabam daquilo que mal deveria ser permitido de ouvir, dos seus apontamentos pessoais que ficam sendo cantarolados e mimetizados, em vez da reverência, da grandeza e do talento. É daí que surge aquele ditado horroroso e distorcido, no entanto comum, de que os nossos oradores discursam com delicadeza, e os atores fazem mímica com fluência."

26.4 "É claro, eu não negaria que Cássio Severo, o único que o nosso amigo Apro ousou nomear, se for comparado àqueles que vieram depois, poderia ser chamado de orador, ainda que na maior parte dos seus escritos ele tenha mais bile que substância. Ao desprezar a ordem dos assuntos, ao negligenciar a boa medida e o decoro do vocabulário, e ao ser desorganizado mesmo em relação às próprias armas que usa, muitas vezes se rebaixando por um desejo de machucar, ele foi o primeiro a não entrar em combates, mas em brigas de rua."

26.5 "Além disso, como ia dizendo, comparado aos seus sucessores, ele supera os demais tanto pela riqueza da sua erudição e pelo charme da sua urbanidade, quanto pela firmeza das suas próprias forças; desses, Apro não bancou nomerar, nem, por assim dizer, arregimentar ninguém."

26.6 " $\mathrm{Eu}$, por outro lado, esperava que ele, depois de acusar Asínio, Célio e Calvo, nos apresentaria um outro contingente e os nomearia na maior parte, quem sabe até na mesma quantidade, dos quais um oporíamos a Cícero, outro a César, e entã indivíduo a indivíduo."

26.7 "Agora, contente por ter aviltado os oradores antigos nominalmente, ele não ousou nomear nenhum dos subsequentes, a não ser coletivamente e em termos gerais, creio que com medo de ofender a muitos se selecionasse a poucos."

\footnotetext{
${ }^{15}$ Deletei sicut his clam et, que não faz nenhum sentido na pasagem, embora apareça nos manuscritos.
} 
26.8 "quotus enim quisque scholasticorum non hac sua persuasione fruitur ut se ante Ciceronem numeret, sed plane post Gabinianum?"

"at ego non uerebor nominare singulos, quo facilius propositis exemplis appareat quibus gradibus fracta sit et deminuta eloquentia."
26.8 “Ora, quão ínfimo é o número de estudiosos da retórica que não se aproveitam dessa capacidade de convencimento que têm para se colocarem atrás de Cícero, mas muito à frente de Gabiniano?"

"Eu, porém, não vou ter receio de nomear indivíduos, para que transpareça com mais facilidade dos exemplos dados em que grau está debilitada e diminuída a oratória."

Materno interrompe o discurso, pedindo que Messala se abstivesse de dizer o que todos já sabiam, que os antigos eram melhores, e se ativesse ao tema combinado, antes de Apro o ter irritado com referências a seus parentes. Messala: "non sum” inquit "offensus Apri mei disputatione, nec uos offendi decebit, si quid forte aures uestras perstringat, cum sciatis hanc esse eius modi sermonum legem, iudicium animi citra damnum affectus proferre" 16 (Dial. 27.2). Materno pede que prossiga, fazendo uso da antiga libertas de que, mais que da oratória, tanto seus contemporâneos se afastaram.

28.1 et Messalla: "non reconditas, Materne, causas requiris nec aut tibi ipsi aut huic Secundo uel huic Apro ignotas, etiam si mihi partes assignatis proferendi in medium quae omnes sentimus."

28.2 "quis enim ignorat et eloquentiam et ceteras artes desciuisse ab illa uetere gloria non inopia hominum, sed desidia iuuentutis et neglegentia parentum et inscientia praecipientium et obliuione moris antiqui? quae mala primum in urbe nata, mox per Italiam fusa, iam in prouincias manant."
28.1 E Messala: "Não procurais causas ocultas, Materno, nem que tu desconheças, ou este Segundo aqui, ou mesmo este Apro, ainda que me atribuais o papel de falar publicamente coisas que todos percebemos."

28.2 "Afinal, quem ignora que tanto a oratória como as demais áreas do conhecimento se apartaram daquela antiga grandeza não por incapacidade das pessoas, mas por desinteresse da juventude, por negligência dos pais, por despreparo dos instrutores e pelo esquecimento das antigas tradições? Esses males, que primeiro nasceram em Roma e logo se difundiram pela Itália, já extravasam para as províncias."

\footnotetext{
16 "Não me ofendi”, diz, "com a discussão do nosso Apro, e não vos convém deixar-se ofender se por acaso algo crispar os vossos ouvidos, já que sabeis que é esta a norma em conversas deste tipo, proferir as suas convicções a despeito do dano emocional."
} 
28.3 "quamquam uestra uobis notiora sunt, ego de urbe et his propriis ac uernaculis uitiis loquar, quae natos statim excipiunt et per singulos aetatis gradus cumulantur, si prius de seueritate ac disciplina maiorum circa educandos formandosque liberos pauca praedixero."

28.4 "nam pridem suus cuique filius, ex casta parente natus, non in cellula emptae nutricis, sed gremio ac sinu matris educabatur, cuius praecipua laus erat tueri domum et inseruire liberis. eligebatur autem maior aliqua natu propinqua, cuius probatis spectatisque moribus omnis eiusdem familiae suboles committeretur; coram qua neque dicere fas erat quod turpe dictu neque facere quod inhonestum factu uideretur."

28.5 "ac non studia modo curasque, sed remissiones etiam lususque puerorum sanctitate quadam ac uerecundia temperabat. sic Corneliam Gracchorum, sic Aureliam Caesaris, sic Atiam Augusti $\dagger^{19}$ praefuisse educationibus ac produxisse principes liberos accepimus."

28.6 "quae disciplina ac seueritas eo pertinebat ut sincera et integra et nullis prauitatibus detorta unius cuiusque natura toto statim pectore arriperet artes honestas et, siue ad rem militarem siue ad iuris scientiam siue ad eloquentiae studium inclinasset, id solum ageret, id uniuersum hauriret."
28.3 "Bem entendido, os vossos problemas vos são bem conhecidos; eu vou falar dos próprios e domésticos da capital, os quais arrebatam já os recém-nascidos e se acumulam por cada uma das faixas etárias, mas antes direi algumas coisas sobre a seriedade e a disciplina dos pais em relação à formação e à educação dos filhos."

28.4 "Pois antigamente toda e qualquer criança nascida em uma família de bem era criada não no quartinho de uma ama de leite paga ${ }^{17}$, mas no colo e entre os braços da mãe, cuja principal qualidade era cuidar do lar e devotar-se aos filhos. Não obstante, escolhia-se uma parente mais velha, a cujos modos atestados e aprovados toda a progenitura de uma mesma família seria delegada; na presença dela ${ }^{18}$ não era permitido dizer o que fosse feio de dizer, nem fazer o que parecesse indigno de fazer."

28.5 "Ela punha ordem com algo de integridade e de respeito não nos estudos apenas e nos cuidados, mas nos divertimentos também e nas brincadeiras das crianças. Sabemos que foi assim que Cornélia esteve à frente da educação dos Gracos, Aurélia da de César, Ácia da de Augusto, e assim que formaram filhos exemplares."

28.6 "O objetivo dessa severa disciplina era que a natureza de cada um, pura e intocada, não transviada por nenhuma deturpação, abraçasse desde o começo de peito aberto a alta cultura e, se se inclinasse seja à carreira militar, seja à ciência jurídica, seja ao estudo da oratória, somente nisso trabalhasse, tudo disso extraísse."

\footnotetext{
${ }^{17}$ Paga, por quem comprada no mercado de escravos (o texto latino traz emptae nutricis, literalmente 'ama comprada').

${ }^{18}$ A princípio, "dela" poderia referir-se a "mulher" ou a "progenitura", o que reflete uma ambiguidade do próprio texto latino; Gudeman (1894) apoia a primeira opção, Mayer (2005) a segunda.

${ }^{19}$ Deletei matrem, como sugere Sauppe.
} 
29.1 "at nunc natus infans delegatur Graeculae alicui ancillae, cui adiungitur unus aut alter ex omnibus seruis, plerumque uilissimus nec cuiquam serio ministerio accomodatus; horum fabulis et erroribus et uirides $\uparrow^{20}$ statim et rudes animi imbuuntur, nec quisquam in tota domo pensi habet, quid coram infante domino aut dicat aut faciat."

29.2 "quin etiam ipsi parentes non probitati neque modestiae paruulos assuefaciunt, sed lasciuiae et dicacitati, per quae paulatim impudentia irrepit et sui alienique contemptus."

29.3 "iam uero propria et peculiaria huius urbis uitia paene in utero matris concipi mihi uidentur, histrionalis fauor et gladiatorum equorumque studia. quibus occupatus et obsessus animus quantulum loci bonis artibus relinquit? quotum quemque inuenies qui domi quicquam aliud loquatur? quos alios adulescentulorum sermones excipimus, si quando auditoria intrauimus?"

29.4 "ne praeceptores quidem ullas crebriores cum auditoribus suis fabulas habent, colligunt enim discipulos non seueritat disciplinae nec ingenii experimento, sed ambitione salutationum et illecebris adulationis."

30.1 "transeo prima discentium elementa, in quibus et ipsis parum laboratur nec in auctoribus cognoscendis nec in euoluenda antiquitate nec in notitia uel rerum uel hominum uel temporum satis operae insumitur."
29.1 "Hoje em dia, porém, o bebê nasce e é entregue a alguma criadinha grega, a quem se junta um ou dois de todos os outros escravos, geralmente o de menor valor e que não se encaixa em qualquer tarefa importante; a conversa mole e as asneiras deles logo permeiam as tenras e imaturas mentes, e ninguém na casa inteira considera digno de ponderação o que for falar ou fazer na frente do jovem amo."

29.2 "Não é por menos, os próprios pais não acostumam os pequenos à retidão nem à moderação, mas à licenciosidade e ao deboche, por quais paulatinamente se vai insinuando a falta de vergonha e de respeito por si e pelos outros."

29.3 "Na realidade, parece-me que os problemas próprios e específicos desta cidade são praticamente concebidos no útero da mãe, o apreço pelo teatro e a mania por gladiadores e corridas de cavalo. Uma mente ocupada e tomada por essas coisas que espaço mínimo deixa para a cultura erudita? Quão pouca gente vais encontrar que fale de outra coisa em casa? De que outros assuntos escutaremos os adolescentes falando se em algum momento entrarmos em uma sala de leitura?"

29.4 "Nem mesmo os preceptores falam de outras coisas mais densas com os seus pupilos, pois eles amealham alunos não pela seriedade da disciplina nem pela demonstração do talento, mas pela bajulação dos cumprimentos matinais e por adulações insidiosas."

30.1 "Repasso os primeiros elementos do aprendizado, com os quais também pouco se trabalha, não se dando atenção suficiente nem para descobrir os clássicos, nem para destrinchar a história, nem para o conhecimento dos fatos ou das personalidades ou dos momentos históricos."

${ }^{20}$ Deletei teneri, por parecer uma glossa (Mayer 2005). 
30.2 "sed expetuntur quos "rhetoras" uocant; quorum professio quando primum in hanc urbem introducta sit, quamque nullam apud maiores nostros auctoritatem habuerit, statim dicturus; referam necesse est animum ad eam disciplinam qua usos esse eos oratores accepimus quorum infinitus labor et cotidiana meditatio et in omni genere studiorum assiduae exercitationes ipsorum etiam continentur libris."

30.3 "notus est uobis utique Ciceronis liber, qui Brutus inscribitur, in cuius extrema parte - nam prior commemorationem ueterum oratorum habet - sua initia, suos gradus, suae eloquentiae uelut quandam educationem refert: se apud Q. Mucium ius ciuile didicisse, apud Philonem Academicum, apud Diodotum Stoicum omnes philosophiae partes penitus hausisse, neque iis doctoribus contentum, quorum ei copia in urbe contigerat, Achaiam quoque et Asiam peragrasse, ut omnem omniumartium uarietatem complecteretur."

30.4 "itaque hercule in libris Ciceronis deprehendere licet non geometriae, non musicae, non grammaticae, non denique ullius ingenuae artis scientiam ei defuisse. ille dialecticae subtilitatem, ille moralis partis utilitatem, ille rerum motus causasque cognouerat."

30.5 "ita est enim, optimi uiri, ita ex multa eruditione et plurimis artibus et omnium rerum scientia exundat et exuberat illa admirabilis eloquentia. neque oratoris uis et facultas sicut ceterarum rerum angustis et breuibus terminis cluditur, sed is est orator, qui de omni quaestione pulchre et ornate et ad persuadendum apte dicere pro dignitate rerum, ad utilitatem temporum, cum uoluptate audientium possit."
30.2 "Porém, ficam-se solicitando os chamados "rétores"; deixando para falar em seguida de quando a atuação deles - a qual não teria tido nenhuma autoridade perante os nossos avós - foi primeiro introduzida em Roma, é necessário chamar a atenção para a disciplina que sabemos terem adotado aqueles oradores cujo ilimitado esforço, cotidiana reflexão e constante prática em todos os domínios do conhecimento se conservam inclusive nos seus próprios escritos."

30.3 "É-vos conhecido sobretudo o texto de Cícero intitulado Brutus, em cujo trecho final - antes ele faz uma rememoração dos antigos oradores - indica como parte do desenvolvimento da sua eloquência os seus passos iniciais: aprender direito civil com Quinto Múcio, explorar em profundidade todos os ramos da filosofia com Filão, o acadêmico, com Diodoto, o estoico, e não contente com esses mestres, com muitos dos quais já tivera contato em Roma, peregrinar pela Acaia e também pela Ásia, a fim de abarcar toda a diversidade de todas as ciências."

30.4 "É assim, claro, que se pode depreender dos escritos de Cícero que não the faltou conhecimento de geometria, nem de música, nem de literatura, nem, por fim, de quaisquer outras artes liberais. Ele conhecia a exatidão da lógica, conhecia a utilidade da filosofia moral, conhecia as causas dos movimentos das coisas."

30.5 "Assim que é, senhores, assim que é com base em muita erudição, nas mais variadas disciplinas e no conhecimento, das mais variadas disciplinas e do conhecimento de todos os assuntos que sobra e sobeja aquela admirável eloquência. O poder e a capacidade de um orador não se encerram em limites apertados, estreitos como os das demais matérias, mas é orador aquele que possa discursar bela e ornadamente sobre toda questão, de maneira apta a persuadir de acordo com a elevação do assunto, segundo a conveniência das circunstâncias, e com o prazer dos ouvintes." 
31.1 "hoc sibi illi ueteres persuaserant, ad hoc efficiendum intellegebant opus esse non ut in rhetorum scholis declamarent nec ut fictis nec ullo modo ad ueritatem accedentibus controuersiis linguam modo et uocem exercerent, sed ut iis artibus pectus implerent in quibus de bonis ac malis, de honesto et turpi, de iusto et iniusto disputatur; haec enim est oratori subiecta ad dicendum materia."

31.2 "nam in iudiciis fere de aequitate, in deliberationibus de utilitate, in laudationibus de honestate disserimus, ita $<$ tamen $>$ ut plerumque haec ipsa in uicem misceantur. de quibus copiose et uarie et ornate nemo dicere potest nisi qui cognouit naturam humanam et uim uirtutum prauitatemque uitiorum et intellectum eorum quae nec in uirtutibus nec in uitiis numerantur."

31.3 "ex his fontibus etiam illa profluunt ut facilius iram iudicis uel instiget uel leniat qui scit quid ira, et promptius ad miserationem impellat qui scit quid sit misericordia et quibus animi motibus concitetur."

31.4 "in his artibus exercitationibusque uersatus orator, siue apud infestos, siue apud cupidos, siue apud inuidentes, siue apud tristes, siue apud timentes dicendum habuerit, tenebit uenas animorum et, prout cuiusque natura postulabit, adhibebit manum et temperabit orationem, parato omni instrumento et ad omnem usum reposito."
31.1 'Os antigos estavam convencidos disso e entendiam que para realizá-lo era necessário não declamar nas escolas dos rétores nem fazer exercícios apenas de língua e de voz com controvérsias artificiais e de modo algum atinentes à verdade, mas encher o espírito das disciplinas nas quais se possa debater sobre o bem e o mal, o honroso e o degradante, o justo e o injusto; esses, enfim, são os temas sobre os quais o orador deve discursar."

31.2 "Ora, nos tribunais, em geral, dissertamos sobre a equidade, nas assembleias sobre a utilidade, nas cerimônias sobre a honradez, de tal maneira que, no fim das contas, na maioria das vezes essas coisas acabem se misturando. Ninguém pode discursar sobre esses assuntos de maneira rica, diversificada e ornada, a não ser que tenha travado conhecimento da natureza humana, do significado das virtudes e da corrupção dos vícios, e do entendimento daquilo que não se classifica nem como virtude nem como vício."

31.3 "É dessas fontes que emana também aquilo com que instigará ou aplacará mais facilmente a ira de um juiz quem saiba o que é ira, e levará mais prontamente à comiseração quem saiba o que é misericórdia, e com quais sentimentos ${ }^{21}$ se causará comoção."

31.4 "Um orador versado nessas ciências e práticas, ao ter de discursar para um público hostil ou parcial ou invejoso ou infeliz ou temeroso, tomará o pulso dos ânimos e, dependendo do que a natureza de cada um demandar, administrará a dose e moderará o discurso, com todo o instrumental preparado e pronto para todo uso."

\footnotetext{
${ }^{21}$ A notar que Messala usa o termo um tanto antiquado motus animorum, como Cícero, enquanto que Apro, em seu discurso, usara adfectus.
} 
31.5 "sunt apud quos adstrictum et collectum et singula statim argumenta concludens dicendi genus plus fidei meretur; apud hos dedisse operam dialecticae proficiet. alios fusa et aequalis et ex communibus ducta sensibus oratio magis delectat; ad hos permouendos mutuabimur a Peripateticis aptos et in omnem disputationem paratos iam locos."

31.6 "dabunt Academici pugnacitatem, Plato altitudinem, Xenophon iucunditatem, ne Epicuri quidem et Metrodori honestas quasdam exclamationes assumere iisque, prout res poscit, uti alienum erit oratori."

31.7 "neque enim sapientem informamus neque Stoicorum comitem, sed eum qui quasdam artes haurire, omnes libare debet. ideoque et iuris ciuilis scientiam ueteres oratores comprehendebant et grammatica, musica, geometria imbuebantur, incidunt enim causae, plurimae quidem ac paene omnes, quibus iuris notitia desideratur, plerumque autem in quibus haec quoque scientia requiritur."

32.1 "nec quisquam respondeat sufficere ut ad tempus simplex quiddam et uniforme doceamur. primum enim aliter utimur propriis, aliter commodatis, longeque interesse manifestum est possideat quis quae profert an mutuetur. deinde ipsa multarum artium scientia etiam aliud agentes nos ornat atque ubi minime credas eminet et excellit."
31.5 "Há quem dê mais crédito a um estilo de discurso sucinto, compacto, que encaixa frase a frase, sistematicamente, cada linha de raciocínio; para esses valerá ter-se aplicado à lógica. A outros, agrada mais um discurso flúdo, uniforme, desenvolvido a partir do bom senso; para atingi-los, tomaremos emprestado aos peripatéticos lugares-comuns adequados e já preparados para todos os tipos de debate."

31.6 "Os acadêmicos fornecerão a combatividade, Platão a nobreza, Xenofonte a alegria, e não será estranho ao orador pegar nem mesmo certos ditos decentes de Epicuro ou de Metrodoro e utilizá-los segundo a situação pedir."

31.7 "Também não estamos formando um filósofo, nem tampouco um correligionário dos estoicos, mas alguém que deve esgotar algumas ciências, e degustar de todas. É por isso que os antigos oradores tanto se apropriavam de conhecimentos de direito civil, quanto se incutiam de noções de literatura, música e geometria, afinal surgem processos - os mais numerosos de fato, quase todos - aos quais faz falta o domínio do direito; aliás, neles, geralmente, essa mesma ciência também está em debate."

32.1 "E que ninguém retruque que é suficiente sermos ensinados algo simples e básico segundo a ocasião. Primeiro porque usamos do que é nosso de um jeito, e do que é emprestado de outro, e manifestamente há uma enorme diferença entre alguém possuir o que fica exibindo ou tomar emprestado. Depois, o próprio conhecimento das muitas disciplinas nos equipa ao fazermos outras coisas, e onde menos esperarias aparece e salta aos olhos." 
32.2 "idque non doctus modo et prudens auditor, sed etiam populus intellegit ac statim ita laude prosequitur, ut legitime studuisse, ut per omnes eloquentiae numeros isse, ut denique oratorem esse fateatur. quem non posse aliter existere nec extitisse umquam confirmo nisi eum qui, tamquam in aciem omnibus armis instructus, sic in forum omnibus artibus armatus exierit."

\section{3 "quod adeo neglegitur ab horum tempo-} rum disertis, ut in actionibus eorum $<\mathrm{hu}>$ ius quoque cotidiani sermonis foeda ac pudenta uitia deprehendantur, ut ignorent leges, non teneant senatus consulta, ius ciuitatis ultro derideant, sapientiae uero studium et praecepta prudentium penitus reformident."

32.4 "in paucissimos sensus et angustas sententias detrudunt eloquentiam uelut expulsam regno suo, ut quae olim omnium artium domina pulcherrimo comitatu pectora implebat, nunc circumcisa et amputata, sine apparatu, sine honore, paene dixerim sine ingenuitate, quasi una ex sordidissimis artificiis discatur."

32.5 "ego hanc primam et praecipuam causam arbitror cur in tantum ab eloquentia antiquorum oratorum recesserimus. si testes desiderantur, quos potiores nominabo quam apud Graecos Demosthenem, quem studiosissimum Platonis auditorem fuisse memoriae proditum est?"
32.2 "Percebe-o não apenas o ouvinte estudado, especialista, mas também o povo, e logo passa a acompanhar com tal aprovação quem se aplicou devidamente, quem percorreu todos os tópicos da oratória, que acaba por reconhecer que esse é, enfim, um orador. Orador que não se pode vir a ser de outro jeito, asseguro, nem que jamais veio a ser, senão aquele que, assim como teria ido para a guerra equipado de todas as armas, tenha ido para o fórum armado de todas as artes."

32.3 "Isso é a tal ponto negligenciado pelas pessoas fluentes de hoje, que nas suas sustentações em juízo, e também na atual conversação cotidiana, encontram-se os defeitos horrorosos e vergonhosos de não conhecerem as leis, não terem traquejo com os decretos do senado, além de zombarem do direito romano, ${ }^{22}$ e mesmo de torcerem o rosto com força para o estudo da filosofia e os preceitos dos sábios."

32.4 "Eles reduzem a oratória a pouquíssimos parágrafos e a estreitas frases de efeito, como que expulsa do seu reino, como se aquela que outrora, senhora de todas as ciências, preenchia as mentes com o seu belíssimo séquito, agora seja aprendida amputada, castrada, sem pompa, sem honra, diria que quase sem berço, como só uma dentre as mais baixas ocupações."

32.5 "Eu acredito que essa seja a primeira e a principal causa de por que nos afastamos em tão larga medida da eloquência dos antigos oradores. Se se desejam testemunhas, quem melhor indicarei que Demóstenes, entre os gregos, que ficou para a história como tendo sido um atentíssimo ouvinte de Platão?"

\footnotetext{
${ }^{22}$ A expressão latina é ius ciuitatis, de significado obscuro, possivelmente uma imitação de Cícero em Leg. 1.14, em que parece ser um sinônimo para ius ciuile (Mayer, 2005). Gudeman (1894) sugere emendar ius suae ciuitatis, significando o direito específico da cidade ou província de origem de cada orador, mas nesse caso o mais natural seria ius suarum civitatum. Na dúvida, a tradução "direito romano" foi adotada por significar algo igualmente ambíguo e mal definido. Outras possibilidades seriam ius huius ciuitatis, "direito desta cidade", ou seja, de Roma, ou instituta ciuitatis, "instituições da cidade", "instituições sociais".
} 
32.6 "et Cicero his, ut opinor, uerbis refert quicquid in eloquentia effecerit, id se non rhetorum officinis, sed Academiae spatiis consecutum."

32.7 "sunt aliae causae, magnae et graues, quas a uobis aperiri aequum est, quoniam quidem ego iam meum munus expleui et, quod mihi in consuetudine est, satis multos offendi quos, si forte haec audierint, certum habeo dicturos me, dum iuris et philosophiae scientiam tamquam oratori necessariam laudo, ineptiis meis plausisse."
32.6 "Cícero, se não me engano, lembra com estas palavras que, tudo que tenha realizado na oratória, não o obteve nas oficinas dos rétores, mas nas caminhadas da Academia." 23

32.7 "Há outras causas, de grande consequência, as quais é razoável serem reveladas por vós, uma vez - não é? - que eu já cumpri o meu dever e, o que me é de hábito, já ofendi a muitos que, se por acaso tivessem ouvido tais coisas, tenho certeza de que diriam que eu, enquanto cito o estudo do direito e da filosofia como necessários ao orador,os nocauteio com as minhas maluquices."

\section{O segundo discurso, Dial. 33.4 - 35.5}

\section{Abaixo, Messala detalhará os exercícios preparatórios com que os jovens das gerações passadas aprimoravam seus talentos, atendendo à solicitação que Materno lhe fizera em Dial. 33.1.}

33.4 "deinde cum Aper quoque et Secundus idem adnuissent, Messalla quasi rursus incipiens: "quoniam initia et semina ueteris eloquentiae satis demonstrasse uideor docendo quibus artibus antiqui oratores institui erudirique soliti sint, persequar nunc exercitationes eorum."

33.5 "quamquam ipsis artibus inest exercitatio, nec quisquam percipere tot tam reconditas, tam uarias res potest nisi ut scientiae meditatio, meditationi facultas, facultati usus $\dagger^{24}$ accedat; per quae colligitur eandem esse rationem et percipiendi quae proferas et proferendi quae perceperis."
33.4 "Então, assim que Apro e também Segundo assentiram com a cabeça, Messala, como que retomando: "Já que eu aparentemente expus o suficiente sobre os primórdios e as sementes da antiga eloquência ao mostrar com quais matérias os antigos oradores costumavam se educar e refinar, vou agora percorrer as práticas deles."

33.5 "A prática não é parte das ciências em si mesmas, bem entendido, e ninguém pode aprender tantos e tão herméticos, tão variados assuntos, a não ser que ao conhecimento se acrescente a reflexão, à reflexão a capacidade, à capacidade a prática; por aí se conclui que o método para aprender aquilo de que deves tratar e para tratar daquilo que tiveres aprendido é o mesmo."

23 Latim: rhetorum officinis (provavelmente) e Academiae spatiis, tais como em Orator 12.

${ }^{24}$ Deletei eloquentiae (Mayer, 2005). 
33.6 "sed si cui obscuriora haec uidentur isque scientiam ab exercitatione separat, illud certe concedet: instructum et plenum his artibus animum longe paratiorem ad eas exercitationes uenturum quae propriae esse oratorum uidentur."

34.1 "ergo apud maiores nostros iuuenis ille qui foro et eloquentiae parabatur, imbutus iam domestica disciplina, refertus honestis studiis, deducebatur a patre uel a propinquis ad eum oratorem qui principem in ciuitate locum obtinebat."

34.2 "hunc sectari, hunc prosequi, huius omnibus dictionibus interesse siue in iudiciis siue in contionibus adsuescebat, ita ut altercationes quoque exciperet et iurgiis interesset utque, sic dixerim, pugnare in proelio disceret."

34.3 "magnus ex hoc usus, multum constantiae, plurimum iudicii iuuenibus statim contingebat in media luce studentibus atque inter ipsa discrimina, ubi nemo impune stulte aliquid aut contrarie dicit quominus et iudex respuat et aduersarius exprobret, ipsi denique aduocati aspernentur."

34.5 "igitur uera statim et incorrupta eloquentia imbuebantur et, quamquam unum sequerentur, tamen omnes eiusdem aetatis patronos in plurimis et causis et iudiciis cognoscebant. habebantque ipsius populi diuersissimarum aurium copiam, ex qua facile deprehenderent quid in quoque uel probaretur uel displiceret."
33.6 "Mas se alguém considera isso menos claro, e se essa pessoa separa o conhecimento da prática, isto certamente vai aceitar: uma mente instruída e embebida dessas ciências estará de longe mais preparada para as práticas vistas como próprias dos oradores."

34.1 "Assim, entre os nossos ancestrais, o jovem que se preparava para o fórum e para a eloquência, já imbuído da educação doméstica, bem dotado de cultura literária, era levado pelo pai ou por um parente próximo ao principal orador que havia na comunidade."

34.2 "Costumava-se ir atrás dele, acompanhá-lo, presenciar todas as suas elocuções, seja nos tribunais, seja nas assembleias populares, de maneira a que assistisse também aos debates legais e se presenciassem as pequenas causas ${ }^{25} \mathrm{e}$, por assim dizer, se aprendesse a lutar como na guerra."

34.3 "Disso, logo sucedia aos jovens que se preparavam para a vida pública uma grande prática, muito autocontrole e o máximo de senso crítico em meio mesmo aos momentos decisivos, em que ninguém diz impunemente coisas estúpidas ou contraditórias que causem o repúdio do juiz e o protesto do adversário, e no fim a aversão dos próprios defensores."

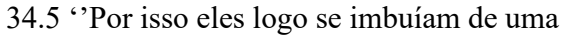
oratória genuína e impoluta e, ainda que seguissem a um só, acabavam por travar conhecimento, durante os mais variados processos e julgamentos, de todos os patronos da mesma geração, e tinham uma profusão dos mais diversos paladares próprios do povo, do que facilmente depreendiam o que em cada caso teria aprovação ou desagradaria."

\footnotetext{
${ }^{25}$ Em latim, iurgium, uma espécie particular de procedimento legal não litigioso, ou litigioso de menor monta, entre vizinhos de terrenos contíguos (Peck 1897).
} 
34.6 "ita nec praeceptor deerat, optimus quidem et electissiumus, qui faciem eloquentiae, non imaginem praestaret, nec aduersarii et aemuli ferro, non rudibus, dimicantes, nec auditorium semper plenum, semper nouum ex inuidis et fauentibus, ut nec bene nec male dicta dissimularentur. scitis enim magnam illam et duraturam eloquentiae famam non minus in diuersis subselliis parari quam suis, inde quin immo constantius surgere, ibi fidelius corroborari."

34.7 "atque hercule sub eius modi praeceptoribus iuuenis ille de quo loquimur, oratorum discipulus, fori auditor, sectator iudiciorum, eruditus et assuefactus alienis experimentis, cui cotidie audienti notae leges, non noui iudicum uultus, frequens in oculis consuetudo contionum, saepe cognitae populi aures, siue accusationem susceperat siue defensionem, solus statim et unus cuicumque causae par erat."

34.8 "nono decimo aetatis anno L. Crassus C. Carbonem, uno et uigesimo Caesar Dolabellam, altero et uicesimo Asinius Pollio C. Catonem, non multum aetate antecedens Caluus Vatinium iis orationibus insecuti sunt, quas hodieque cum admiratione legimus."

35.1 "at nunc adulescentuli nostri deducuntur in scholas istorum qui rhetores uocantur, quos paulo ante Ciceronis tempora extitisse nec placuisse maioribus nostris ex eo manifestum est quod a Crasso et Domitio censoribus cludere, ut ait Cicero, ludum impudentiae iussi sunt."

35.2 "sed ut dicere institueram, deducuntur in scholas in $^{27}$ quibus non facile dixerim utrumne locus ipse an condiscipuli an genus studiorum plus mali ingeniis afferant."
34.6 "Assim, nem faltava um preceptor, por sinal o melhor e mais seleto, que exibisse a face da eloquência, não uma sombra, nem adversários e rivais com armas de ferro, não de madeira, nem uma audiência sempre cheia, sempre renovada de torcedores pró e contra, de sorte que nem as coisas bem nem as mal colocadas ficassem escondidas. Sabeis, enfim, que aquela grande e duradoura reputação da eloquência não se granjeia menos nos assentos da oposição do que nos seus próprios, e na realidade de onde mais resoluta ela se levanta, aí é que mais firme ela se fortalece."

34.7 'Do mais, meus caros, com preceptores desse nível, aquele jovem de que falamos, discípulo de oradores, ouvinte do fórum, acompanhante de julgamentos, refinado e familiarizado com a experiência dos outros, de quem as leis são conhecidas, os rostos dos juízes não são novos, o hábito das assembleias diuturnamente à vista, o gosto do povo sempre discernido, assumisse ele a acusação ou a defesa, prontamente ficava, por conta própria, sozinho, à altura de qualquer causa."

34.8 "Aos dezenove anos de idade Lúcio Crasso investiu contra Caio Carbão, aos vinte e um César contra Dolabela, aos vinte e dois Asínio Polião contra Caio Catão, Calvo, não muito mais velho, contra Vatínio, com discursos que ainda hoje lemos com admiração."

35.1 "Agora, no entanto, os nossos adolescentes são levados para as escolas desses que se chamam de rétores, os quais surgiram pouco antes da época de Cícero e tanto não agradavam aos nossos antepassados, que os censores Crasso e Domício lhes ordenaram fechar, como diz Cícero, o ginásio do descaramento. ${ }^{26 "}$

35.2 "Mas, como me tinha posto a falar, eles são levados para escolas nas quais não é fácil dizer se é o próprio lugar, se são os colegas, se são os tipos de práticas que mais fazem mal aos talentos."

\footnotetext{
${ }^{26}$ Referência à fala de Catão em De Orat. 3.99.

${ }^{27}$ Mayer (2005) e Winterbottom e Olgivie (1975).
} 
35.3 "nam in loco nihil reuerentiae est in quem nemo nisi aeque imperitus intrat; in condiscipulis nihil profectus, cum pueri inter pueros et adulescentuli inter adulescentulos pari securitate et dicant et audiantur; ipsae uero exercitationes magna ex parte contrariae."

35.4 "nempe enim duo genera materiarum apud rhetoras tractantur, suasoriae et controuersiae. ex his suasoriae quidem ${ }^{28}$ tamquam plane leuiores et minus prudentiae exigentes pueris delegantur, controuersiae robustioribus assignantur, quales per fidem et quam incredibiliter compositae! sequitur autem ut materiae abhorrenti a ueritate declamatio quoque adhibeatur."

35.5 "sic fit ut tyrannicidarum praemia aut uitiatarum electiones aut pestilentiae remedia aut incesta matrum aut quicquid in schola cotidie agitur, in foro uel raro uel nunquam, ingentibus uerbis prosequantur. cum ad ueros iudices uentum..."
35.3 "Pois não há nada de deferência em um lugar no qual ninguém entra sem ser igualmente inexperiente; nada de vantagem quanto aos colegas, quando tanto discursem como assistam meninos em meio a meninos e rapazes em meio a rapazes; na verdade, os próprios exercícios são, em maior parte, prejudiciais."

35.4 "Sobretudo, dois gêneros de matérias são tratados com os rétores, as suasórias e as controvérsias. Deles, as suasórias, por exemplo, sendo francamente mais leves e exigindo menos proficiência, são dadas aos meninos, e as controvérsias confiadas aos mais velhos, e por graça, como são compostas de modo inverossímil! Segue-se, ademais, que também o estilo declamatório fica associado a matérias avessas à realidade."

35.5 "É assim que acontece de recompensas para tiranicidas, ou de escolhas de moças estupradas, ou de remédios para a peste, ou de infidelidades conjugais maternas, ou de qualquer coisa de que se fale todo dia na escola, no fórum raramente ou nunca ser elaborado com grande palavrório. Quando se chega a juízes de verdade..."

Aqui, uma lacuna, presente em todos os manuscritos conhecidos do Diálogo, interrompe o texto. No trecho seguinte disponível, já é Materno quem fala.

\title{
Agradecimentos
}

\author{
Gostaria de agradecer ao Prof. Dr. Adriano Scatolin pela cuidadosa \\ leitura preliminar deste artigo e pelas horas que dedicou a discuti emendas \\ a diversos pontos problemáticos do texto latino e da tradução.
}

${ }^{28}$ Leitura incerta. 


\section{Referências}

BORNECQUE, H.; GOELZER, H. Tacite. Dialogue des Orateurs. Paris : Editora Les Belles Lettres, 1906 (Collection Budé).

CLAUSERET, C. Étude sur la langue de la rhétorique et de la critique littéraire dans Cicéron. Cambridge: Cambridge University Press, 1886.

GUDEMAN, A. P. Cornelii Taciti Dialogus de Oratoribus. Boston : Ginn \& Company, 1894.

HEUBNER, H. Cornelii Taciti libri qui supersunt. II Dialogus de Oratoribus. Stuttgart : De Gruyter, 1983 (Bibliotheca Scriptorum Graecorum et Romanorum Teubneriana).

MAYER, R. Tacitus. Dialogus de Oratoribus. Cambridge: Cambridge University Press, 2005 (Cambridge Latin and Greek Classics).

PECK, H. Harper's Dictionary of Classical Literature and Antiquities. New York : Harper \& Brothers, 1897.

REQUEJO, R. Tácito. Agrícola, Germania, Diálogo Sobre Los Oradores. Madrid : Editorial Gredos, 1981 (Biblioteca Clásica Gredos).

WINTERBOTTOM, W.; OLGIVIE, R. P. Cornelii Taciti opera minora. Oxford : Oxford Clarendon Press, 1975 (Oxford Classical Texts).

Recebido em: 16 de abril de 2021 . Aprovado em: 22 de junho de 2021. 
